\title{
MUITA SERVENTIA
}

\author{
Roberto Reis *
}

Mulher tem muita serventia, o senhor nem imagina. Ajuda até na politica. Dá filhos pra gente, impōe respeito. Pro resto, tem as raparigas...

- Jorge Amado, Gabricla, Cravo e Canela.

érgio Buarque de Holanda, em livro hoje clássico, escreveu que a família era modelo obrigatório de qualquer composição social no Brasil (Holanda 106). Antes de aprofundar tal registro, convém prestar atenção à advertência de Dante Moreira Leite: o conceito de familia patriarcal se aplica a uma pequena parcela da sociedade e deve ser visto como unidade de poder (Leite 282) e não como passivel de explicar a organização social como um todo - erro em que incorreram ideólogos do porte de um Gilberto Freyre, cuja obra, ainda segundo Moreira Leite, é "escrita e interpretada do ponto de vista da classe dominante" (Leite 281).

Feita a ressalva, vale a pena explorar o termo e desentranhar algumas de suas implicaçōes. No mesmo Raizes do Brasil, Sérgio Buarque salienta que a própria palavra 'família' deriva de famulus, trazendo no bojo de sua etimologia a idéia de servidão (Holanda 49). Com efeito, a família patriarcal era, no final das contas, uma forma de organização do poder, estruturada hierarquicamente e cujo desenho último poderia ser figurado em uma série de círculos concêntricos: no centro, todo-poderoso, o senhor de terras

*University of Minnesota 
(prevaléncia de uma ordem senhorial), que acumula os papéis de pai (prevaléncia de uma ordem patriarcal) e de homem (prevaléncia de uma ordem masculina). No àmbito da casa-grande, diretamente sob o mando do senhor, a esposa e os filhos; quanto mais afastado deste núcleo emanador de poder, goza de menos prestigio a posiçāo social do individuo, o que esclarece por que todos queriam agasalhar-se sob as asas do ocupante do centro. A presença de uma pessoa neste centro é fundamental para que se definam os demais lugares sociais. E, no mais externo dos círculos, no patamar da piràmide social, o escravo (prevalência de uma ordem escravocrata).

A organizaçāo patriarcal da familia encontra a sua contrapartida, na esfera cconómica, na escravidāo, ocasionando uma extrema polaridade na estratificação social brasileira, estruturada basicamente em torno da relação senhor-escravo. Ao redor deste setor organizado, oscilam dispersos os chamados "homens livres", aspeados porque no fundo são dependentes de um grande, com quem interagem mediante o mecanismo do favor.

Tal configuração do senhoriato estamental brasileiro perdura até as vésperas da Revolução de 30: o patriarca - dono absoluto de sua propriedade, de sua família, de seus servos - se transforma, depois da libertação dos escravos, no coronel e, em seguida, no chefe político que decide as questões através de suas preferências pessoais e suas relações de familia e amizade (Leite 283). Com a urbanizaçāo do pais, a "aristocracia" rural passa a ocupar novos cargos, para os quais carrega a mentalidade familiar. Mas a estrutura senhorial estava abalada e a familia patriarcal ia aos poucos se decompondo: 1930 representa a ruptura de um tipo de articulaçāo da sociedade brasileira, resultando no fim da hegemonia dos proprietários de terras ligados à exportação de produtos como o cafe; significa ainda a fratura de uma forma de relaçāo entre centro e periferia e da ideologia elitista e liberal, que irrigava todo o sistema, já minada desde os anos 20 . Mas a relevanncia da família se arraigou no inconsciente social, legando marcas como o patemalismo e o filhotismo protecionista, que ainda hoje tèm tränsito em larga escala e deterioram as relaçōes politicas no pais.

O desenho da organização social brasileira - estruturada, no àmbito das clites dominantes, em cima da familia - propicia um enfrentamento da situação da mulher, ainda dentro dos mesmos estamentos senhoriais.

Como regra geral, a mulher de classe superior era submissa ao marido. Dentro de casa e com relaçāo à parentela, desenvolvia intensa atividade, sendo raras a indoléncia e a passividade (Queiroz 193) - mas, seguramente, dando ordens as escravas que, estas sim, executavam de fato 
o grosso dos serviços domésticos. Antonio Cândido, estudando a instituição da familia, procura corrigir a imagem lendäria que alguns escritores pintaram da mulher, mostrando que ela estava incumbida de uma função ativa e distinta daquela que competia ao homem: ela dirigia o trabalho dos escravos, a confeç̧ão de roupas, providenciava a comida, tomava conta dos filhos (Cândido 296).

O que está me importando ressaltar agora é este hiato lacunoso entre o que supostamente era a realidade e sua representação no universo simbólico, seja em textos ficcionais, seja no próprio discurso cultural. Preciso transcrever as seguintes palavras de Maria Inácia D`Avila Neto:

o significado da "autoridade patriarcal" pode se resumir aqui muito esquematicamente: nosso sistema patriarcal apresentou diferentes modos de dominaçāo na relaçảo homem-mulher, variando conforme a cor da pele ou a camada social da mulher, ou seja sua "classe-cor". Nosso sistema patriarcal foi ambiguo, se considerarmos que, enquanto o patriarca era senhor absoluto de sua mulher, pmle, escravos, inclusive com direito de morte sobre eles, a mulher era glorificada através de modelos ideais. Essa idealizaçāo esteve ai estreitamente ligada à perpet uação dos tabus sexuais. O Culto à Virgem foi uma rica fonte de preconceitos ainda bastante tenazes entre nós. A VIRGEM, frequïentemente associada à mulher branca, idealizada como imagem de mulher pura, jamais tocada em seu sexo, juntou-se à crença nos "poderes mágicos" e "af rodisíacos" das mestiças, mito, aliás, até hoje explorado pelo nosso espetáculo de exponação turística.

Foi exatamente através da "sexual idade exaltada" da mulata, de seus "feitiços, dengues e quindins", como chamaram alguns expositores da cultura brasileira, ou, em contraposição, a negaçào do sexo, no caso da mulher branca, que nasceram os aspectos de idealizaçāo mística/e ou mágica das mulheres no sistema patriarcal. O patriarca que tinha, além da mulher legitima, as escravas, que the prestavam também serviços sexuais, constituia muitas vezes familias paralelas. Esse estado de coisas serviu para cristalizar preconceitos em torno da natureza poligama do homem (em oposição di mulher talhada para um só amor) eo princípio da dupla moral, que caracterizam o que chamou $\mathrm{E}$. Willens de o "complexo de virilidade" do homem brasileiro (D`Avila Neto 6).

Ora, interessa-me destacar a ambigüidade no tratamento da mulher no discurso cultural brasileiro: de um lado é tida como submissa ao homem; 
de outro, cria-se o mito da mulher pura, merecedora de um amor espiritualizado, quando pertencente às frações superiores, cujo oposto é a atraçāo carnal pelas mulheres de cor, decantada em sua sexualidade, que invariavelmente pertencem a grupos sociais menos privilegiados. Isto inclusive pode ser fisgado em textos literários, nos quais a senhora desperta um desejo que é recalcado (e que se desloca, metafórica ou metonimicamente - e os exemplos seriam abundantes), enquanto a mulata e a negra, mesmo pelo fato de serem escravas ou de baixa condição social, relacionadas de alguma maneira à propriedade, quando focalizadas franqueiam a manifestação franca do desejo e são submetidas à posse pelo senhor e patriarca ou pelos nhonhôs brancos. Esta bifurcação com referência à mulher subsiste até os nossos dias no comportamento da sociedade e na literatura brasileira e se vislumbra, no último caso, mesmo num poeta da envergadura de um Drummond.

Em outras palavras e explicitando minha tese - o romance brasileiro do século passado, de um modo geral, como que desenha, no que tange às práticas amorosas, um quadro ideal, que muito pouco corresponde de fato ao cotidiano social que the era contemporâneo (é sabido como os grandes proprietários rurais, e mesmo seus filhos, mantinham relações com escravas e geravam uma infinidade de filhos bastardos, a ponto de muitas senhoras não consentirem negras belas como escravas). Tal retrato é "puritano", pintando a família como um espaço santo, purificado, para o qual convergem os conjuges, desde que nivelados socialmente, e no qual vivem afastados, com conotações bucólicas, do convivio social, em contacto com a natureza. Ou seja: a narrativa se trai e há uma captação enviesada da realidade, fornecendo um auto-retrato do senhoriato patriarcal nesse gesto mesmo de mascarar o cotidiano oitocentista. E se inscrevendo, desse modo, dentro de um projeto ideológico global: trata-se de uma literatura que, através de noçōes como a de nacionalismo, acaba armando uma justificativa para a hegemonia da elite senhorial que estava no poder.

O encobrimento já é flagrado na tática de evitar a tematizaçāo ficcional da questão candente do século XIX no Brasil: a escravidão. Como ja tratei em detalhe o problema em outra parte (Reis 19-51), limito-me a retomá-lo $\mathrm{cm}$ termos bastante sumários, apenas para dar seqüencia à reflexão, objeto deste trabalho.

O romance brasileiro oitocentista como que evita tratar a escravatura. Seria, em derradeira instancia, colocar a sociedade senhorial face a face com suas próprias mazelas. Embora não disponhamos de dados conclusivos a 
este respeito, é bastante razoável supor que os leitores da época (minguado público, composto sobremodo de mulheres e estudantes) pertencessem ou quisessem pertencer às elites dominantes; de igual modo, os escritores utilizaram seu talento como forma de ascensão, buscando o aconchego do senhoriato ou mesmo do Estado monárquico; e, para situar esta literatura no estreito círculo senhorial, assinalo que ela se debruça sobre estes mesmos setores (caso, em particular, dos romances urbanos) ou, quando aborda os segmentos periféricos (como nos romances sertanistas ou indianistas), o faz desde um enfoque centrado, que apreende o outro, não localizado no centro de poder, a partir de uma ótica masculina, patriarcal, senhorial.

O fato de a escravidão, que salta aos olhos ao problematizarmos o século passado brasileiro, não estar presente não quer dizer que ela não se revestisse de importância. Devemos deduzir justamente o contrário: seu escamoteamento, ao se branquear personagens como Isaura (de $A$ Escrava Isaura, de Bernardo Guimaräes) ou a ausência de escravos em um Alencar, por exemplo, indicam que o assunto inquietava a mauvaise conscience dos estamentos senhoriais. Concordando mais uma vez com Dante Moreira Leite, a questão do escravismo, sustentáculo da vida social e econômica, "não poderia ser discutida pela classe dominante, enquanto que a classe dominada não tinha acesso à cultura" (Leite 289). Seu debate pelas camadas mais populares, em vista disso, teria que ser vasculhado em outras manifestaçōes culturais, sendo a literatura uma forma elitista no Brasil.

Ao recalque ao nível da antecena do texto - onde, via de regra, se narra uma intriga sentimental - corresponderá um deslocamento do assunto para a esfera das relações amorosas, provocando a emergência das contradições sociais nos bastidores inconscientes do fundo de cena romanesco e contradizendo o projeto contestador da narrativa, que se revela, afinal, uma mera reduplicadora dos valores em voga. Daí o amor tirano (a metáfora está em Senhora, de Alencar), que escraviza e implica submissão e domínio, mas no inocente âmbito das relaçōes entre enamorados, nunca entre verdadeiros senhores ou escravos.

Tendo-se em mente que a condição de escravo implica inferioridade social, caberia examinar quais os personagens que são dados como "escravos" na relação amorosa. Tal análise conclui que "senhor" ć o homem branco e "escravos" do amor são o sertanejo (o homem interiorano), o indio, a mulher. Esta, se for de situação social superior ao homem (o que ocorre quando este é indio ou sertanejo), será a "senhora"; se estiverem no mesmo 
plano, socialmente falando, ela sera a "escrava", sujeita aos postulados masculinos e patriarcais, do amor tirano.

Idêntico tipo de enviesamento, que camufla na antecena o tropeço ideológico do fundo de cena, se detectaria nos textos indianistas. $O$ índio comparece para preencher a necessidade de forjar uma origem heróica, lendária, nobre e etnicamente pura para a "aristocracia" mestiça do pais recém-independente e se inscreve no projeto de edificação de uma mitologia nacional. O selvagem ficcionalizado pelos románticos será um cavaleiro medieval de tanga (vestido para não escandalizar a moral vitoriana dos grupos senhoriais) e tacape, que preza valores como a honra e que não representava, ao contrário do negro, qualquer ameaça à ordem escravocrata vigente. $O$ indio contemporàneo, entretanto - o que vivia na miséria, escorraçado para os confins das florestas ou degradado e aculturado nas cidades em crescimento -, nāo consistia um tema literário (Leite 172).

Nas sessōes anteriores trabalhei a coincidéncia, em termos de um desacordo entre a realidade cotidiana do século XIX e sua representação simbólica, pinçável tanto no discurso cultural quanto ao nivel do discurso ficcional brasileiro. Vale frisar que é esta flutuação entre ideário e realidade que dita o tom da vida ideológica do tempo, causando a sensação de as idéias estarem fora de lugar para evocar arguto ensaio de Roberto Schwarz. Importando o liberalismo para um contexto escravocrata, o Romantismo para uma sociedade que não conhecera nada análogo à Revolução Francesa ou à Revoluçāo Industrial, o oitocentos brasileiro se assemelha a um torcicolo (a expressão é de novo de Schwarz), ensejando uma vida cultural o mais das vezes escapista, ornamental e mascaradora.

Estou em condições de voltar as minhas atençōes para o tratamento da ligura da mulher no romance brasileiro do século XIX. Foge aos meus propósitos fazê-lo de modo exaustivo, mesmo porque, salvo eventuais exceçōes (como Dona Guidinha do poço, de Manuel de Oliveira Paiva) e com pequenas variantes (como a exacerbaçāo naturalista e patológica da sexualidade, em $A$ Carne, de Júlio Ribeiro, ou a sutileza psicológica e a ambigüidade moral dos personagens femininos machadianos), o padrão detectado é recorrente: a mulher de certa posição social é pura è casta, despertando um amor espiritualizado (apenas alma, corpo sublimado e recalcado), submissa e "escrava" do homem, seu "senhor", se este for da mesma condição social que ela, ocasiāo em que estará destinada a ser a esposa, no espaço santificado e recolhido da familia. em caso contrário, como ficou mencionado, ela será a "senhora". Se for de um grupo social- 
mente inferior, em especial se for de cor, aguçará desejos lascivos e será objeto de um amor físico e carnal (veja-se o caso de Rita Baiana, de $O$ cortiço, de Aluísio Azevedo, ou de Margarida de O Seminarista, de Bernardo Guimaräes). A mulher está para senvir ao homem, o qual, muitas vezes, ascende graças a ela, a quem é negada a mobilidade social. Em $O$ Garimpeiro, também de Bernardo Guimarães, Elias e o Major (o primeiro em vias de ser homem da "boa sociedade" e o segundo um fazendeiro em apuros financeiros) são os favorecidos com o casamento, em que Lúcia representa um valor de troca, e com o trabalho de Simão, o criado. Convém ainda sublinhar que tal situação transcende o oitocentos brasileiro, chegando até nossos dias: em Jorge Amado a mulher branca é melhor situada econômicamente e socialmente, é chata e insossa, ao passo que a mulata é apimentada (boa de cama e mesa), sensual e entra em cena para abrir as pernas, como acontece em Capitäes da Areia. Ou seja: teriamos que esperar por autores como Clarice Lispector ou Lygia Fagundes Telles, por exemplo, para presenciar um equacionamento realmente diverso da questão da mulher. Embora se possa escrever que é o homem quem dá a identidade da protagonista em Uma Aprendizagem, ou que a falta da figura paterna é um empecilho para que Raíssa se descubra a si mesma, em Verāo no Aquário, penso que as escritoras mulheres lograrão mais éxito em capturar o magma feminino na literatura brasileira contemporânea.

Gostaria de encerrar este estudo percorrendo um dos "perfis de mulher" de José de Alencar.

Em Luciola (1862), Paulo e a narrativa que narra tentam conciliar a antitética imagem que se desprende de Lúcia. $O$ narrador não consegue compreender que a menina casta e pura seja uma mulher, cortesã e necessita resolver o paradoxo. No primeiro caso, terá que reprimir o seu desejo; no segundo, poderá dar livre vasão ao gozo e ao prazer.

Lúcia paulatinamente se metamorfoseia, alimentada pelo amor de Paulo, na purificada e angelical Maria da Glória. Tendo internalizado as marcas dos grupos sociais dirigentes, ela fica obcecada pela ambiçāo de pureza. Enquanto Maria da Glória, ela adere a uma vida recatada, nega o corpo ao ex-amante que, persistindo seu desejo, só pode externá-lo dando "um beijo na ponta da botina que aparecia sob a orla do vestido" de Lúcia (Alencar 187).

Porque a Lúcia que interessa a Paulo é a dos "bons dias", que o engolfava "num mar de voluptuosidades" (Alencar 148). Vale dizer: a Lúcia sexo, corpo. Seu desejo nunca desaparece, ao passo que o de Lúcia, bem 
mais reprimido, se extravasa na cena do "último beijo" (Alencar 213) ou se transfere, deslocado primeiro para o ser chamado de Maria da Glória e, em seguida, para a "suprema delicia" que coloca em cena sua irmā, Ana, que ela oferece a Paulo: "não acharás alma tão pura, nem mais casto amor" (Alencar 220).

Lúcia pinta o amor como "coesão de almas" (Alencar 217), amor sem interesse que despreza o corpo e que ela associa à "felicidade dos que tèm uma familia" (Alencar 40). Lúcia, apesar de transformada em anjo, carrega o estigma do passado de cortesã. Ela almeja ser pura, uma senhora e nāo uma mulher (a distinção é feita pelo texto), pois a senhora pode pertencer à "boa sociedade", anseio também de Paulo. No contexto patriarcal, a esposa é a reprodutora de filhos, mulher de respeito e de familia. Nesta esfera puritana, da camada senhorial, a relaçāo física está recalcada e o amor sexual, liberador do prazer, está reservado para as mulheres, em espaço outro que nāo o núcleo familiar.

Lúcia, ao propor a Paulo que se case com Ana, insinua que ele precisa "criar uma familia e gozar das santas afeições domésticas" (Alencar 219 ), que ela não se sente capaz de lhe proporcionar. A familia se delineia como o lugar edenico, sublime, para o qual converge a máxima felicidade. $O$ anseio de se recolher em contacto com a natureza e levar uma existência pacata e retirada da sociedade reconte em Alencar. Nảo raro os rapazes que povoam seus textos urbanos despendem a mocidade em "loucuras", que procuram esquecer ao se casarem, refugiando-se na familia.

Lúcia estaria na iminència de ingressar neste espaço sacralizado. Entretanto, Maria da Glória, tendo a "alma virgem", sendo um anjo, ainda percebe em si uma nódoa de culpa e não se acha gabaritada para desposar Paulo e oferecer-lhe os "castos prazeres". Só na morte, que implica a destruição total do corpo e que enseja o "santo consórcio" das duas almas, ela poderá se redimir por completo, expiando o pecado de se ter vendido. Pagando pela ousadia de, tendo sido "mulher", querer ter a vã pretensāo de ser "senhora".

Paulo, que anseia ascender socialmente, não pode denegrir sua imagem de homem de bem, permitindo que sua honra seja manchada com a fama de que está envolvido com uma cortesã. Iniciando uma "vida séria" (Alencar 169), necessitando de aprovação social, a morte de Lúcia é imprescindivel para que ele prossiga em seu caminho. A Lúcia, ainda que transfigurada na santa e pura Maria da Glória, apesar de ter uma pequena fortuna (notória credencial para o prestigio) é vetada a salvação. Tendo 
transgredido com o corpo o contex to puritano e moralista, não pode se tornar uma dama. Lúcia quis trocar de posição e para tal buscou abraçar novos valores. Na verdade, perdeu o seu lugar social, pois deixou de ser cortesã; mas não lhe consentem, pelo fato de tê-lo sido, pertencer à "boa sociedade" c aproximar-se do núcleo senhorial. Querer sair do lugar que lhe estava previamente estipulado, lugar em que sua presença ganhava sentido, seria subverter a cerimónia santa do casamento. Não é facultado, no entanto, violar a fronteira que separa o espaço da castidade (a familia) do espaço do prazer (pré ou extraconjugal), a alma do corpo, as senhoras das mulheres, limite que decreta as posições e os papéis sociais a serem desempenhados pelos individuos. Papéis que, como ficou escrito mais atrás, na sociedade brasileira, no seio dos estamentos dominantes, eram designados a partir da figura do patriarca.

Enfatizemos a contradição do texto. À primeira vista, Luciola critica a sociedade do tempo, que produzia "Lúcias". Inocentar a protagonista e condenar esta sociedade parece ser, ao que tudo indica, o intento primeiro desta narrativa de José de Alencar. Todavia, embora imponha a "musa cristā", mártir da sociedade, o romance a imola, por assim dizer, não a perdoa, repisando os mesmos valores que parecia atacar, Couto, Cunha, Sá, o próprio Paulo (a não ser pelo fato de querer exumar, pela escritura, a "Lúcia dos bons dias") saem incólumes.

A intriga amorosa que se declara na antecena textual, na verdade oblitera estes aspectos sociais. A ótica que preside o texto é duplamente masculina: a do narrador Paulo e, mais significativo, a da sociedade aí retratada. Consente-se aos homens a realização de seus desejos (desde que com cortesãs) e se lhes reserva as meninas inocentes para os "santos gozos" do amor conjugal. A sociedade, que se mostra tão complacente com a prática amorosa dos mancebos, tende a discriminar as mulheres - basta estarem desacompanhadas para não serem olhadas como "senhoras" (Alencar 30). Só com as cortesãs é que se abrem as portas da "mansão do prazer" - mas para a sociedade masculina. Para a mulher da "boa sociedade", que tem que manter a compostura, está sublimado o gozo, o amor carnal, entendido como prazer. Visão romântica, sem dúvida. Muito mais interessante é relevar seu vinculo com a sociedade brasileira do Segundo Império. Sociedade, já o sabemos, patriarcal, senhorial, masculina e escravagista.

O desejo carnal e o prazer são tolerados no âmbito masculino, desde que com cortesās (ou escravas), visto ser o espaço familiar puro e casto, cerceador do prazer. Às personagens femininas socialmente instaladas no 
centro dos círculos concêntricos é reservado o culto do amor idealizado, espiritual, carregado de conotaçōes religiosas. Há, pois, um duplo recalque: do amor fisico, marcado negativamente, e da mulher. Esta, por seu turno, ć forçada a decidir em qual pólo se situa: no da familia, lugar das senhoras e meninas inocentes, da castidade; ou no do gozo, protagonizado por cortesās ou mulheres de condição social inferior ou de cor. À mulher é vedado o trânsito social e a ambigüidade de acumular os dois extremos. Ao homem, contudo, se faculta circular de um para o outro, já que a organizaçāo social se estrutura de modo a beneficiar a ordem masculina.

A abordagem de Luciola nos aponta o caráter hierárquico (repressor e autoritário) da sociedade ai abarcada. E nos ilustra a questão da mulher neste mesmo contexto. O romance de Alencar como que elabora um panorama ideal: implicitamente enaltece a familia e coloca a cortesã $e m$ seu ligar, afastando-a do senhoriato que ocupa o centro do poder. Como que purificando o cotidiano sexual do oitocentos brasileiro, por um lado, mas deixando entrever sua face última por trás da máscara urdida pela narrativa.

Lúcia, heroina no fundo inferiorizada, é comparada em várias passagens a uma escrava. Senhor é Paulo. Luciola é um "lampiro noturno" - um inseto social.

\section{REFERÊNCIAS BIBLIOGRÁFICAS}

ALENCAR, José de. Luciola. Rio de Janeiro: Ouro, s/d.

CANDIDO, Antonio. "The Brazilian Family". Brazil, Ponrair of Halfa Continent. Ed T.Lynn Smith. New York: Drysden, 1951. p.291-312.

D'AVILA NETO, Maria Inácia. "O autoritarismo e a mulher brasileira". Jornal do Brasil, Rio de Janeiro, 7 set 1980. Cademo Especial, p.6.

FREYRE, Gilherto. Ca.sa-grande \& semzala. 19.ed. Rio de Janeiro: José Olympio, 1978.

HAHNER, June. A mulher no Brasil. Rio de Janeiro: Civilizaçāo Brasileira, 1978.

HOLANDA, Sérgio Buarque de. Raizes do Brasil. 12. ed. Rio de Janeiro: José Olympio, 1978. LEITE, Dante Moreira. O caráter nacional brasileiro. 2. ed . Sāo Paulo: Pioneira, 1969.

QUEIROZ, Maria Isaura Pereira de. O mandonismo local na vida politica brasileira. São Paulo: Alfa-Omega, 1976.

REIS, Robeno. A permanéncia do circulo - hierarquia no romance brasileiro. Nitenoi/Brasilia: EDUFF/INL. 1987.

SAMARA, Eni de Mesquita. A familia brasileira. Säo Paulo: Brasiliense, 1983.

SCHWARZ, Roherio. Ao vencedor, as batatas. Säo Paulo: Duas Cidades. 1977. 